\title{
Presence or Absence of Microbiome Modulates the Response of Mice Organism to Administered Drug Nabumetone
}

\section{Lenka JOUROVÁ ${ }^{1}$, Barbora LIŠKOVÁ ${ }^{3}$, Kateřina LNĚNIČKOVÁ ${ }^{1}$, Nina ZEMANOVÁ ${ }^{1}$, Pavel ANZENBACHER ${ }^{2}$, Petra HERMANOVÁ ${ }^{4}$, Tomáš HUDCOVIC ${ }^{4}$, Hana KOZÁKOVÁ ${ }^{4}$, Eva ANZENBACHEROVÁ ${ }^{1}$}

${ }^{1}$ Department of Medical Chemistry and Biochemistry, Faculty of Medicine and Dentistry, Palacky University, Olomouc, Czech Republic, ${ }^{2}$ Department of Pharmacology, Faculty of Medicine and Dentistry, Palacky University, Olomouc, Czech Republic, ${ }^{3}$ Institute of Molecular and Translational Medicine, Faculty of Medicine and Dentistry, Palacky University Olomouc, Czech Republic, ${ }^{4}$ Institute of Microbiology, Czech Academy of Sciences, Novy Hradek, Czech Republic

Received October 8, 2020

Accepted October 18, 2020

\section{Summary}

The gut microbiota provides a wide range of beneficial functions for the host, and has an immense effect on the host's health status. The presence of microbiome in the gut may often influence the effect of an orally administered drug. Molecular mechanisms of this process are however mostly unclear. We investigated how the effect of a nonsteroidal drug nabumetone on expression of drug metabolizing enzymes (DMEs) in mice intestine and liver is changed by the presence of microbiota, here, using the germ free (GF) and specific pathogen free (SPF) $\mathrm{BALB} / \mathrm{C}$ mice. First, we have found in a preliminary experiment that in the GF mice there is a tendency to increase bioavailability of the active form of nabumetone, which we have found now to be possibly influenced by differences in expression of DMEs in the GF and SPF mice. Indeed, we have observed that the expression of the most of selected cytochromes P450 (CYPs) was significantly changed in the small intestine of GF mice compared to the SPF ones. Moreover, orally administered nabumetone itself altered the expression of some CYPs and above all, in different ways in the GF and SPF mice. In the GF mice, the expression of the DMEs (CYP1A) responsible for the formation of active form of the drug are significantly increased in the small intestine and liver after nabumetone application. These results highlight the importance of gut microbiome in processes involved in drug metabolism in the both gastrointestinal tract and in the liver with possible clinical relevance.

\section{Key words}

Gut microbiome • Cytochromes P450 • Germ-free mice • Nabumetone $\bullet$ Metabolism of drugs

\section{Corresponding author}

K. Lněničková, Department of Medical Chemistry and Biochemistry, Faculty of Medicine and Dentistry, Palacky University Olomouc, Hnevotinska 3, CZ-775 15 Olomouc, Czech Republic. E-mail: Katerina.Inenickova@upol.cz

\section{Introduction}

Inter-individual differences in the ability to metabolize drugs may cause a variability in their pharmacokinetic level and thus the response of patients to therapy. Intestinal and hepatic cytochrome P450s (CYPs) are responsible for the biotransformation of most clinically used drugs, and they are considered to be one of the main sources of this enormous variability (Anzenbacher and Anzenbacherova 2001). The expression of CYPs is affected by a unique combination of mechanisms and factors including genetic polymorphism, modulation by xenobiotics, regulation by cytokines and/or hormones, pathological status of the organism as well as gender, age and other factors (Zanger and Schwab 2013). Over the past couple of years, the human gut microbiome has received increasing attention as a potential regulator of the metabolism of drugs (Jourova et al. 2016, Li et al. 2016, Wilson and Nicholson 2017).

Dozens of drugs have been reported to undergo direct microbial modification (Jourova et al. 2016, Saad et al. 2012, Sousa et al. 2008). Some recent studies have 
shown that altering the composition of the gut microbiome may affect the pharmacokinetics of orally taken drugs, with implications for their oral bioavailability (Jourova et al. 2019, Matuskova et al. 2014, Yoo et al. 2014). The drugs themselves, especially antibiotics, may change the composition of the gut microbiota, and their coadministration may lead to drug-drug interactions and interindividual differences in treatment efficacy (Jernberg et al. 2010, Wilkinson et al. 2018).

Both microbiota-mediated alterations in drug metabolism and drug-mediated alterations in the gut microbiome can exhibit beneficial, but likewise detrimental effects on the host. Better understanding of this intricate mutual drug metabolism-gut microbiome relationship could make a significant contribution to improving treatment efficacy and may contribute to avoiding undesirable side-effects. In most cases, however, the detailed molecular mechanism, the specific reaction, as well the bacterial strain involved in drugmicrobiome interaction, is not yet fully understood.

The results from a few recent studies indicate that one of the possible mechanisms of action of the gut microbiome in terms of influencing drug bioavailability may be its impact on the expression of hepatic biotransformation enzymes (Jourova et al. 2017, Selwyn et al. 2015, Selwyn et al. 2016). We recently found that colonization by only a single non-pathogenic or probiotic bacteria strain alters the mRNA expression of some hepatic CYPs in originally germ-free mice (Jourova et al. 2017).

However, since an oral route is the most commonly used route for drug application, it is mainly the small intestine which is the first site of exposure of a drug to the metabolic system, and to its absorption with high potential of the first-pass metabolism (Kaminsky and Zhang 2003). Besides the presence of trillions of microorganisms, the small intestine expresses biotransformation enzymes including CYPs, and thus it can metabolize the drug directly, hence reducing its bioavailability (Xie et al. 2016). Better understanding of the regulation of the intestinal and liver CYPs, their involvement in first-pass metabolism and the role of the gut microbiota here, may be crucial for improving drug efficacy and enhancing the bioavailability of new drugs in development.

Nabumetone (4-(6-methoxy-2-naphthyl)-2butanone) is a widely used non-acidic, non-steroidal antiinflammatory prodrug. After oral administration, nabumetone is converted by oxidative cleavage of its side chain to its active metabolite 6-methoxy-2-naphthylacetic acid (6-MNA), a strong inhibitor of cyclooxygenase-2 (Nobilis et al. 2013). We have found recently that nabumetone is metabolized by gut microbiota to its pharmacologically inactive metabolite (Jourova et al. 2016). Moreover, using rodent models with altered gut microbiome we have observed that this bacterial contribution in metabolism of nabumetone may have consequences for its bioavailability. Mice completely lacking the microbiota (germ-free, GF) appeared to be more effective in formation of active form of the drug, 6-MNA (Jourova et al. 2019). Formation of 6-MNA has been ascribed to CYP1A2 with contribution of CYP3A4 (Turpeinen et al. 2009, Varfaj et al. 2014).

In this study, the expression of mRNA and protein and enzymatic activity of intestinal and hepatic CYPs was determined in GF and specific-pathogen-free (SPF) mice after the administration of nabumetone.

\section{Materials and Methods}

\section{Chemicals}

The BCA assay kit was obtained from SigmaAldrich (St. Louis, MO, USA). Protease inhibitor cocktail tablets (EDTA free Complete Protease Inhibitor Cocktail Tablets) were supplied by Roche (Basel, Switzerland). Hydrochloric acid (p.a., $37 \%$ ) was supplied by Penta (Prague, Czech Republic), sodium chloride and dimethyl sulfoxide were obtained from Lach-Ner (Neratovice, Czech Republic). Acetonitrile was supplied by VWR International (Radnor, Pennsylvania, USA) and it was obtained in the highest purity available. 7-ethoxyresorufin and 7-ethoxy-4-(trifluoromethyl)coumarin were supplied by Sigma-Aldrich. Midazolam was purchased from Abcam (Cambridge, UK). Western blotting was done using a chemiluminescence kit from Santa Cruz Biotechnology (Heidelberg, Germany). Protein standard for electrophoresis was obtained from Bio-Rad (Hercules, CA, USA). Primary monoclonal rabbit anti-mouse CYP2B10 antibody was purchased from Merck (Darmstadt, Germany). Mouse monoclonal antibody CYP1A1, rabbit CYP3A antibody, secondary antibodies and $\beta$-actin antibody used as a loading control were obtained from Santa Cruz Biotechnology. Commercially available primers were purchased from Life Technologies (Carlsbad, CA, USA) (Table 1). RNA later solution was purchased from Quiagen (Dynex, Czech Republic). All other chemicals, which were of HPLC or analytical grade, were obtained from Sigma-Aldrich. 
Table 1. List of primers used for qPCR. Commercial TaqMan Gene Expression Assays were ordered from Thermo Fisher Scientific (Life Technologies, Carlsbad, CA, USA).

\begin{tabular}{lr}
\hline Gene Symbol & Assay ID \\
\hline Cyp1a1 & Mm00487218_m1 \\
Cyp1a2 & Mm00487224_m1 \\
Cyp2a5/4 & Mm00487248_g1 \\
Cyp2b10 & Mm00456591_m1 \\
Cyp2c29 & Mm00725580_s1 \\
Cyp2c38 & Mm00658527_m1 \\
Cyp2d22 & Mm00530542_m1 \\
Cyp2e1 & Mm00491127_m1 \\
Cyp3a11 & Mm00731567_m1 \\
Cyp3a13 & Mm00484110_m1 \\
Hprt & Mm03024075_m1 \\
Ahr & Mm00478932_m1 \\
HNF4 & Mm01247712_m1 \\
CAR & Mm00486717_m1 \\
PXR & Mm.8509 \\
\hline
\end{tabular}

\section{Animals and experimental design}

The experiment was carried out in accordance with Czech Act No. 359/2012 Coll. for the protection of animals against abuse. All procedures with animals were approved by the Ethics Committee, Ministry of Education of the Czech Republic. Experiments were approved by the Committee for the Protection and Use of Experimental Animals of the Institute of Microbiology. v.v.i., Academy of Sciences of the Czech Republic (approval ID: 50/2011).

Germ-free (GF) and specific-pathogen-free (SPF) inbred BALB/c mice were used for the experiment. GF mice were born and housed under sterile conditions in Trexler-type plastic isolators and fed $50 \mathrm{kGy}$ irradiated sterile pellet diet Altromin 1410 (Altromin, Lage, Germany) and sterile water ad libitum. Fecal samples were evaluated weekly for the presence of aerobic and anaerobic bacteria, molds and yeast by the standard microbiological methodology. SPF mice were kept in IVC cages (Tecniplast, Italy) and fed with the same sterile diet as their gnotobiotic counterparts. SPF mice were regularly checked for the absence of potential pathogens according to an internationally established standard (FELASA). Animals were kept in a room with a $12 \mathrm{~h}$ light-dark cycle at $22^{\circ} \mathrm{C}$. Two-month-old mice were used for our experiments. There were 18 mice in both experimental models (i.e. 18 mice in GF and 18 mice in SPF), 3 mice per each time point $(1,2,3,4$ and 8 hours after nabumetone treatment) and three individuals from GF and SPF mice without nabumetone treatment served as controls.

The non-steroidal anti-inflammatory drug nabumetone 4-(6-methoxy-2-naphthyl)-2-butanone was applied as a single oral dose $(15 \mathrm{mg} / \mathrm{kg})$ to both groups of mice. The mice were euthanized at 1, 2, 3, 4 and 8 hours after nabumetone application by cervical dislocation and exsanguination. The livers and small intestines were aseptically removed, weighed, frozen in liquid nitrogen and subsequently stored at $-70{ }^{\circ} \mathrm{C}$ until further processing.

\section{RNA isolation and Quantitative Real-Time PCR ( $q P C R$ )}

To determine the mRNA expression of CYP, samples of small intestine and liver were used from GF and SPF mice in the first three hours after the application of nabumetone (e.i. pooled data from first three timepoints) and from the control group without nabumetone. Total RNA was isolated from tissue samples stored in RNAlater (Qiagen, Hilden, Germany) using an RNeasy Plus Mini Kit (Qiagen). RNA concentration and purity were determined spectrophotometrically, and the RNA integrity was verified by gel electrophoresis. First strand cDNA was synthesized from total RNA with a Transcriptor High Fidelity cDNA synthesis kit (Roche). Real-time PCR for CYPs quantification was performed in a LightCycler 1536 Instrument (Roche) using a specific TaqMan Gene Expression Assays (Applied Biosystems, Life Technologies, Waltham, Massachusetts, USA). The 1536-well plates were pipetted using an Automate Labcyte Echo (Dublin, Ireland).

The calculations were based on the "Delta-Delta Ct method" (Livak and Schmittgen 2001). The data was expressed as the fold change in the treatment groups relative to the control, and HPRT1 and $18 \mathrm{~S}$ rRNA were used as an internal control.

\section{Preparation of subcellular fractions}

Microsomal fractions were obtained from the liquid nitrogen-frozen liver and small intestine of mice. Pooled livers and small intestines were homogenized in homogenization buffer, $\mathrm{pH} 7.4$ (0.25 M sucrose, $1.0 \mathrm{mM}$ EDTA), using an ULTRA-TURRAX T 25 basic (IKA,Staufen, Germany). The buffer for homogenization was supplemented with protease inhibitor cocktail tablets (Roche). The subcellular fractions were separated by the different centrifugation speeds of the liver/intestinal homogenate (Gillette 1971) and the microsomal fractions 
were stored at $-80^{\circ} \mathrm{C}$. Protein concentrations in the microsomal fractions were assayed using BCA protein assay according to the manufacturer's instructions. The concentration of CYP enzymes in obtained microsomes was determined using difference spectroscopy (Phillips and Shephard 2006).

\section{Western blotting}

Before a Western blot performing, total protein concentration was determined using the BCA protein assay. Microsomal proteins (50 $\mu \mathrm{g} /$ well) of mice liver and small intestine were separated using 4-15\% MiniPROTEAN TGX Precast Protein Gels (Bio-Rad) and subsequently transferred onto polyvinylidene fluoride membranes $(0.45 \mu \mathrm{m})$ using Trans-Blot Turbo Transfer System (Bio-Rad). The membranes were blocked in $5 \%$ non-fat dry milk/TBS-Tween-20 for $2 \mathrm{~h}$ and incubated with primary antibodies overnight at $4{ }^{\circ} \mathrm{C}$. Followed incubation was performed with the appropriate secondary antibodies for 1 hour at room temperature. Immunodetection of CYPs was done using primary antibodies: CYP1A1 at 1:100 dilution, CYP2B1/2 at 1:200 dilution, and CYP3A at 1:200 dilution (see Chemicals section). The used antibodies are orthologs of human CYP1A1/2, CYP2B10 and CYP3A4. The $\beta$-actin antibody (diluted 1:500) was used as a loading control for normalization. The bands were visualized with respective horseradish peroxidase-conjugated secondary antibodies using the chemiluminiscence kit (see Chemicals section). Image Studio ${ }^{\mathrm{TM}}$ Lite 5.0 (LI-COR Biosciences, Lincoln, NE, USA) software was used for the relative quantification of protein bands.

\section{Enzyme assays}

Enzyme activities were assayed in the microsomal fractions from homogenate of mouse small intestine. The amount of organic solvents in the final reaction mixtures did not exceed $1 \%(\mathrm{v} / \mathrm{v})$. Enzyme activities of selected CYP enzymes were measured according to established methods (Chang and Waxman 2006). Substrates of orthologous human forms (as listed under Chemicals) were used. The following microsomal CYP activities were tested: CYP1A1/2, 7-ethoxyresorufin O-deethylation, CYP2B6, 7-pentoxyresorufin O-depenthylation, and CYP3A activity, midazolam 1'-hydroxylation. All determinations were done in duplicates. Activities were measured using HPLC Prominence system (Shimadzu, Kyoto, Japan) with a UV/ fluorescence detection. The measurements were performed in a LiChrospher RP-18 column or a Chromolith ${ }^{\circledR}$ High Resolution RP-18 endcapped column (determination of midazolam substrate) (Merck). The HPLC conditions are given in Table 2.

Table 2. Conditions and HPLC parameters for the measurement of enzyme activity.

\begin{tabular}{|c|c|c|c|c|c|c|c|c|c|}
\hline CYP & Substrate & Metabolite & $\begin{array}{c}\text { Substrate } \\
\text { concentration } \\
(\mu \mathrm{M})\end{array}$ & $\begin{array}{c}\text { pmol of } \\
\text { CYP/ } \\
\text { incubation } \\
\text { volume }(\boldsymbol{\mu l})\end{array}$ & $\begin{array}{c}\text { Quenching } \\
\text { agent }\end{array}$ & Elution & $\begin{array}{c}\text { Injection } \\
\text { of sample } \\
(\mu \mathrm{l})\end{array}$ & $\begin{array}{c}\text { UV } \\
(\mathrm{nm})\end{array}$ & $\begin{array}{l}\text { etection } \\
\text { Fluorescence } \\
\text { Ex/Em (nm) }\end{array}$ \\
\hline $1 \mathrm{~A} 1 / 2$ & $\begin{array}{l}\text { 7-Ethoxy- } \\
\text { resorufin }\end{array}$ & Resorufin & 2.6 & $35 / 100$ & $\begin{array}{c}100 \% \\
\text { methanol }\end{array}$ & Isocratic & 50 & & $535 / 585$ \\
\hline $2 \mathrm{~B}$ & $\begin{array}{c}\text { 7-ethoxy-4- } \\
\text { (trifluoromethyl) } \\
\text { coumarin }\end{array}$ & $\begin{array}{c}\text { 7-hydroxy-4- } \\
\text { (trifluoromethyl) } \\
\text { coumarin }\end{array}$ & 15 & $35 / 100$ & $\begin{array}{c}100 \% \\
\text { methanol }\end{array}$ & Isocratic & 50 & & $410 / 510$ \\
\hline $3 \mathrm{~A}$ & Midazolam & $\begin{array}{l}\text { 1'-Hydroxy- } \\
\text { midazolam }\end{array}$ & 2.8 & $12.56 / 100$ & $\begin{array}{c}100 \% \\
\text { methanol }\end{array}$ & Isocratic & 50 & 240 & \\
\hline
\end{tabular}

\section{Statistics}

All data are expressed as means \pm SD. Statistical calculations were done using Statistica 12 (StatSoft Inc., Tulsa, OK, USA). Statistical significance was determined using an unpaired Student's t test or Mann-Whitney U test. Differences were regarded as statistically significant when the $\mathrm{P}$ value was lower than 0.05. Software GraphPad Prism 8 (GraphPad Software Inc., California, USA) was used to create the graphs. 


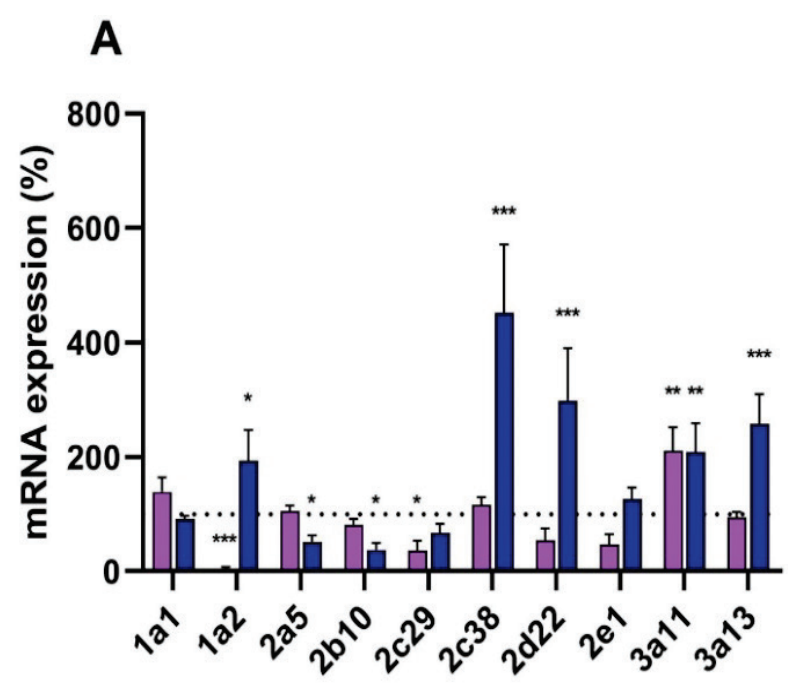

B

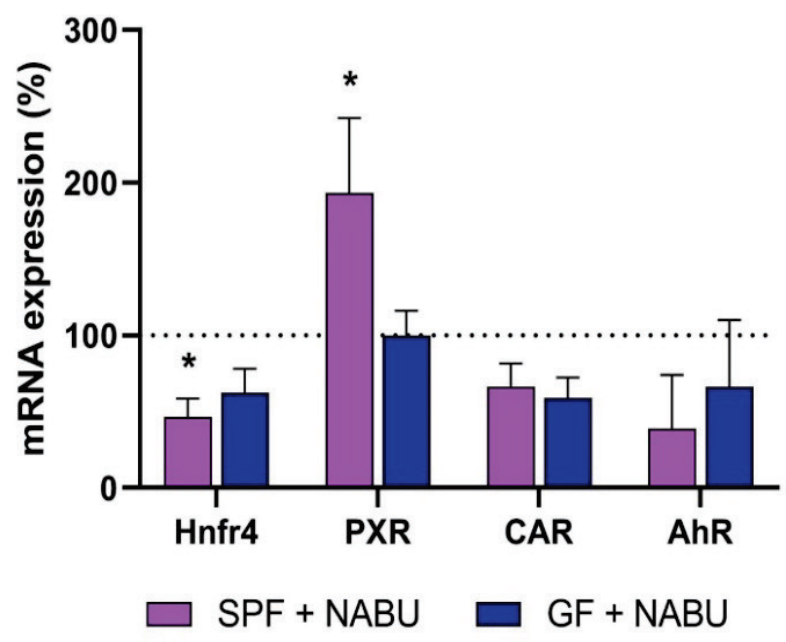

Fig. 1. Influence of nabumetone on mRNA expression of CYPs (A) and transcription factors (B) in small intestine of SPF and GF mice in first three hours after one dose application. Data are expressed as percentage of the respective SPF/GF untreated control. mRNA data represent the mean \pm SD. from 9 individual animals. Values significantly increased or decreased $(* \mathrm{P}<0.05$, $* * \mathrm{P}<0.01, * * * \mathrm{P}<0.001)$ in comparison with the control are labeled. NABU - nabumetone.

\section{Results}

Nabumetone influences the intestinal gene expression of CYPs and transcriptional factors in the GF and SPF mice

We have observed the effect of orally applied nabumetone on the CYP gene expression in the small intestine of GF and SPF mice. Interestingly, applied nabumetone influenced the CYP gene expression differently in the GF and SPF mice. The expression of Cypla2, 2c38, 2d22, $3 a 11$ and $3 a 13$ was significantly increased in the GF mice treated with nabumetone in comparison with the untreated GF group. The expression of the Cyp3a11 gene was increased in the SPF mice after the administration of nabumetone (Fig 1A). On the other hand, the expression of several genes was decreased in the SPF mice, the most significant changes were observed with the Cypla2 mRNA levels (Fig. 1A).

In addition, four transcriptional factors were chosen to determine the influence of nabumetone on the regulation of Cyp expression - hepatocyte nuclear factor 4 (Hnf4), pregnane $\mathrm{X}$ receptor (PXR), constitutive androstane receptor (CAR) and aryl hydrocarbon receptor (AhR). The gene expression of Hnf4 was decreased in the small intestine of SPF mice and the same tendency was observed in GF mice as well. The expression of PXR was increased by nabumetone in the small intestine of SPF, while remaining unaffected in GF mice. CAR mRNA level was decreased in the GF and SPF mice. With the mRNA expression of AhR, a slight decrease was observed in both GF and SPF mice in comparison with the control group. (Fig. 1B).

Nabumetone affects the intestinal CYP protein expression in different ways in the GF and SPF mice

Based on the interesting results regarding the intestinal CYP mRNA expression, protein expression of selected CYP was made using Western blotting analysis in the small intestine of GF and SPF mice treated with nabumetone. The protein expression of CYP1A1/2 was increased after application of nabumetone in SPF and, especially in GF mice in comparison with their control group without nabumetone treatment (Fig. 2A). The difference in protein expression in GF and SPF mice was observed in CYP2B1/2 protein (Fig. 2B). In SPF mice, the protein expression of CYP2B1/2 was decreased after application of nabumetone, on the other hand we have observed increase in GF mice (Fig. 2B). The same trend was observed in the protein expression of CYP3A (Fig. 2C), which may be also involved in the metabolism of nabumetone.

Mice lacking the microbiome exhibit higher levels of functional CYPIA in the small intestine after application of nabumetone

As the formation of pharmacologically active metabolite of nabumetone (6-MNA) has been ascribed mostly to CYP1A2 (Turpeinen et al. 2009, Varfaj et al. 2014), we have measured its enzymatic activity by HPLC using ethoxyresorufin, a specific substrate of human CYP1A enzyme. In line with the gene and protein expression we have observed the slight increase in the 
enzyme activity in GF mice treated with nabumetone in comparison with their control GF group (Fig. 3A). In SPF mice, in contrary, we have found a decrease in CYP1A activity caused by nabumetone treatment (Fig. 3A).
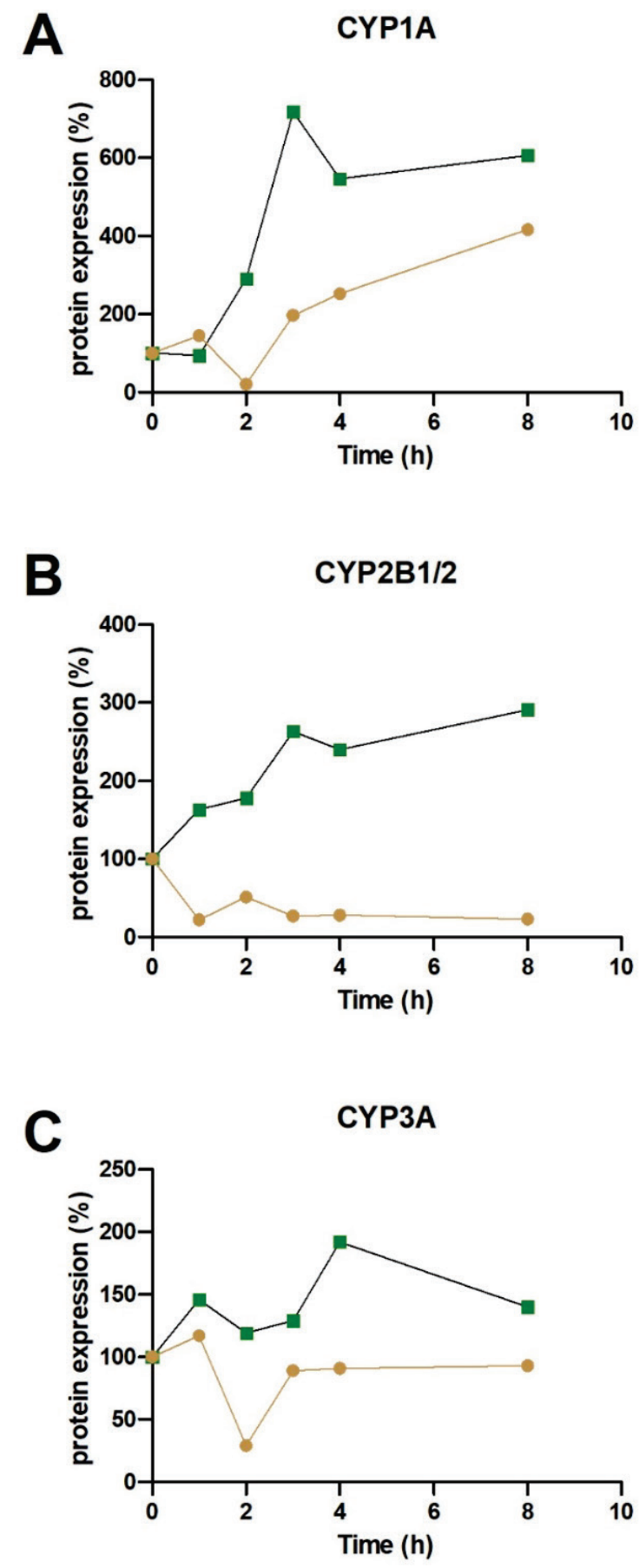

\section{$\mathrm{SPF}+\mathrm{NABU}-\mathrm{GF}+\mathrm{NABU}$}

Fig. 2. The protein expression of CYP1A (A), CYP2B1/2 (B), CYP3A (C) in the small intestine of SPF and GF mice treated with nabumetone in time after one dose application in comparison with their SPF/GF control group (100\%) without nabumetone treatment. Protein relative levels were measured in the pooled microsomal fractions (3 animals per group). NABU nabumetone.
A

\section{CYP1A}

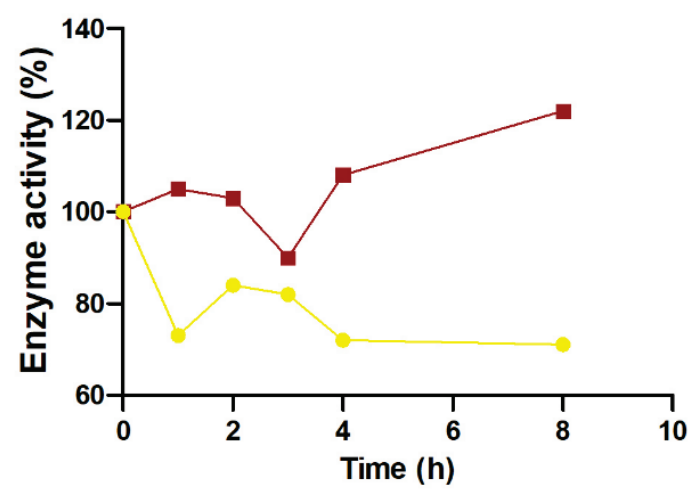

B

CYP2B

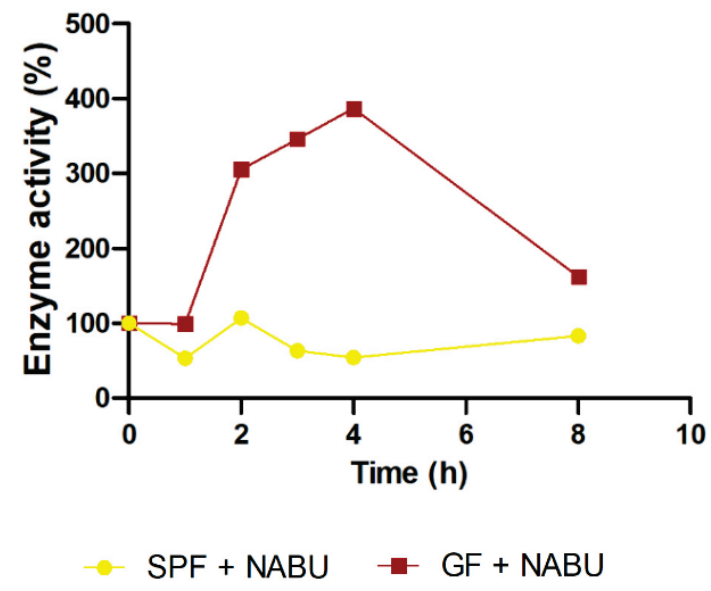

Fig. 3. The enzyme activity of CYP1A (A) and CYP2B (B) in the small intestine of SPF and GF mice treated with nabumetone in time after one dose application in comparison with their SPF/GF control group $(100 \%)$ without nabumetone treatment. Protein relative levels were measured in the pooled microsomal fraction (3 animals per group). NABU - nabumetone.

Besides the enzyme activity of CYP1A, the activity of CYP2B has been determined in the small intestine with intention to clarify whether the significantly changed protein levels represent it's functional form. We observed consistent trend with protein expression (CYP2B activity increase) in GF mice after nabumetone treatment, while CYP2B activity in SPF mice is the same as in their untreated counterparts (Fig. 3B).

Effect of nabumetone on the hepatic gene expression of CYPs and transcriptional factors

To supplement the data obtained in the intestine, we measured the mRNA expression of selected Cyp genes in the liver of GF and SPF mice after the administration of nabumetone (Fig. 4A). In the liver, the patterns of CYP expression differ from those in the small intestine. For example, the gene expression of Cyp3a11 
in liver was not significantly influenced by nabumetone in both GF and SPF mice, unlike the small intestine. The Cypla2 mRNA expression was not affected by nabumetone in GF mice, but it was significantly decreased in SPF mice after nabumetone treatment. The expression of Cyplal was significantly increased by nabumetone in GF mice, while it decreased in the SPF mice. A significant decrease was observed in the expression of Cyp $2 d 22$ in SPF mice (Fig. 4A).

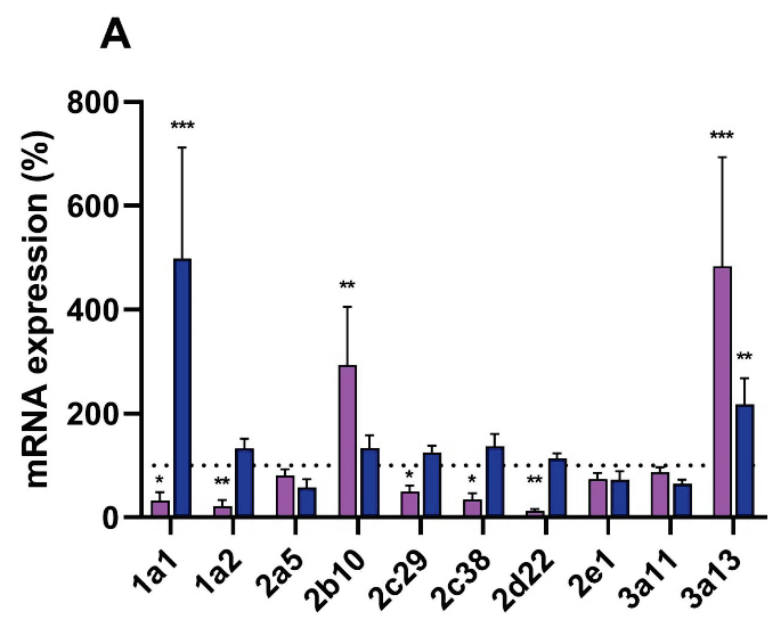

B

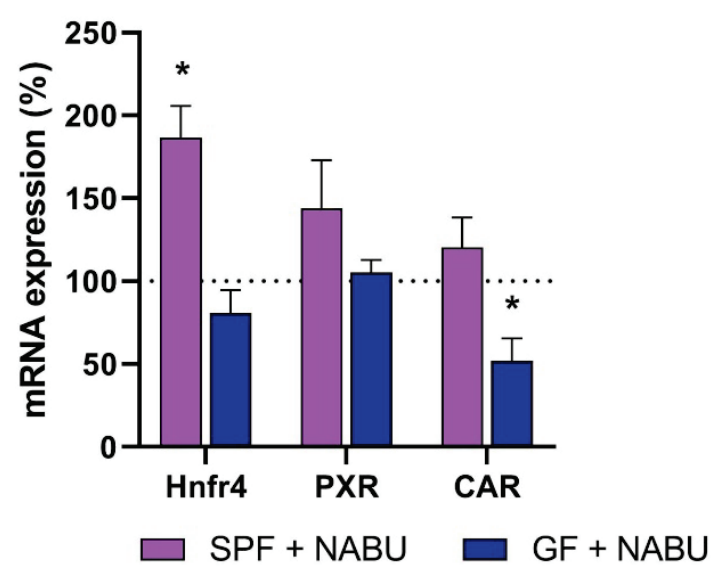

Fig. 4. Influence of nabumetone on mRNA expression of CYPs (A) and transcription factors (B) in liver of SPF and GF mice in first three hours after one dose application (1;2 and 3 hours). Data are expressed as percentage of the SPF/GF control group $(100 \%)$ without nabumetone treatment. The mRNA data represent the mean \pm SD from 9 individual animals. Values significantly increased or decreased $(* \mathrm{P}<0.05 ; * * \mathrm{P}<0.01$; $* * * \mathrm{P}<0.001)$ in comparison with the control are labeled. NABU nabumetone.

Three transcriptional factors were chosen to determine the influence of nabumetone on the regulation of Cyp expression in liver tissue, i.e. Hnfr4, PXR, CAR (Fig. 4B). The gene expression of Hnf4 was significantly increased by nabumetone in the liver of SPF mice. The
mRNA level of PXR was slightly increased, while the expression of CAR was not affected by nabumetone in the liver of SPF mice. In the liver of GF mice, we did not observe any changes in the expression of Hnf4 and PXR, while the CAR expression was decreased.

Effect of nabumetone on the hepatic CYP protein expression

The CYP1A protein was influenced by nabumetone likewise in the liver of GF and SPF mice, but in a different manner. In the first three hours after nabumetone application, the protein expression of CYP1A in GF mice was increased with decreasing tendency in the next five hours. On the other hand, in SPF mice, the protein expression was not significantly changed in the first three hours and it slightly increased in the next five hours (Fig. 5A).

On the other hand, the CYP3A protein expression was significantly increased by nabumetone in the liver of SPF mice in comparison to untreated SPF group. The same, but milder, tendency was apparent in GF mice (Fig. 5B). These results were opposite to the data found in the small intestine (Fig. 2C).

\section{Discussion}

A plethora of papers have reported that the human gut microbiome plays a crucial role in human health and is involved in many important biological functions and is associated with many pathological states such as diabetes mellitus (Forslund et al. 2015), cardiovascular diseases (Koopen et al. 2016), inflammatory bowel diseases (Goethel et al. 2018), atherosclerosis (Koeth et al. 2013) and even neurologic diseases (Cox and Weiner 2018). Based on recent studies, it is evident that the gut microbiome is often involved in the biotransformation of clinically used drugs and may alter their bioavailability, efficacy and toxicity (Jourova et al. 2016, Saad et al. 2012, Wilkinson et al. 2018, Wilson and Nicholson 2017). However, the metabolic activity of intestinal microbiota toward xenobiotics and the effects of interactions between the host organism and the gut microbiome belong among the least explored factors contributing to the inter-individual variability in drug response.

In this study, we investigated how the effect of a nonsteroidal drug nabumetone on expression of DMEs in mice intestine and liver is changed by the presence of microbiota using the GF and SPF mice. 
A

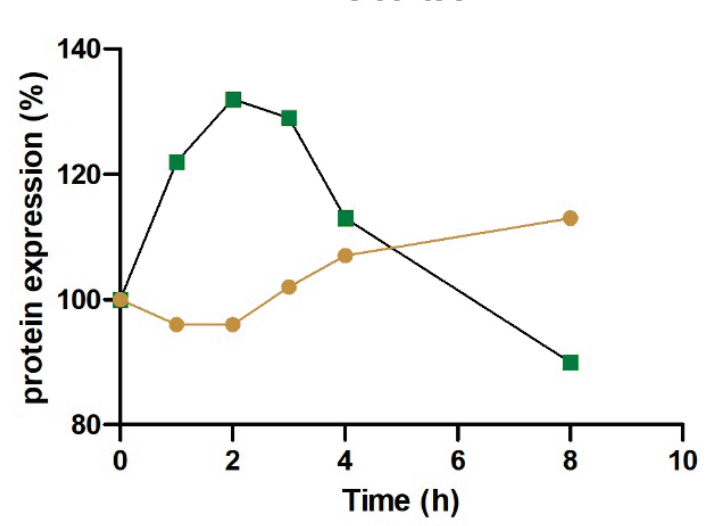

SPF + NABU
B

CYP3A

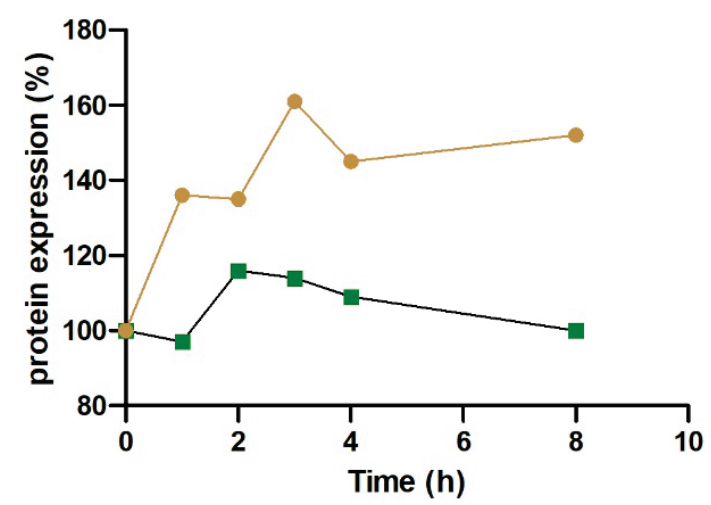

GF + NABU

Fig. 5. The protein expression of CYP1A (A) and CYP3A (B) in the liver of SPF and GF mice treated with nabumetone in time after one dose application in comparison with their SPF/GF control group (100\%) without nabumetone treatment. Protein relative levels were measured in the pooled microsomal fractions ( 3 animals per group).

The mRNA expressions of CYPs in the liver of GF and SPF mice were previously published (Claus et al. 2011, Jourova et al. 2017, Selwyn et al. 2015, Selwyn et al. 2016), unfortunately, with contradictory results. As the intestine is the first line of defense against orally ingested xenobiotica, we determined the mRNA expressions of CYPs in the small and large intestine in SPF and GF mice. We found that mRNA levels of most of selected CYPs were significantly decreased in the small intestine in the absence of gut microbiota compared to mice with bacteria present (Data not shown). In the colon, we have observed the same tendency with slighter changes (Data not shown). These results indicate that the regulation of the expression of the intestinal CYPs (like liver CYPs) is influenced by the presence/absence of gut microbiota, and that there is a direct or indirect interaction between intestinal bacteria and the synthesis of CYPs in the enterocytes of the small intestine.

Not only the presence of trillions of gut microorganisms, but likewise a drug therapy may affect the expression of intestinal and hepatic biotransformation enzymes including CYPs. Indeed, we have found that orally administered nabumetone itself alters the expression of some CYPs in both the intestine and liver, and above all, in different ways in GF mice and SPF mice.

As we have previously found, mice completely lacking the microbiota (GF) appeared to be more effective in formation of the active form of the drug, 6-MNA (Jourova et al. 2019). Formation of 6-MNA has been ascribed mostly to CYP1A2 with contribution of
CYP3A4 (Turpeinen et al. 2009, Varfaj et al. 2014), therefore, we have focused on these enzymes. Interestingly, we have found that the gene and protein expression of Cypla2 and even its enzyme activity was increased in GF mice treated with nabumetone in comparison with untreated GF group in the small intestine. While the SPF mice treated with nabumetone have showed rather opposite, decreasing tendency on the CYP1A2 mRNA levels and activity in comparison with the respective SPF control group. In the liver, the changes in the Cypla2 gene and protein expression were similar (but pronounced to a lesser extent) than those in the small intestine. Mice lacking the microbiome thus may exhibit higher levels of functional intestinal and hepatic CYP1A, which may modulate the response to drugs metabolized by CYP1A including nabumetone itself.

$\mathrm{AhR}$ is a ligand-activated transcriptional factor that has various endogenous functions, and is responsible for the induction of biotransformation enzymes such as CYP1A1, CYP1A2, CYP1B1, glutathione S-transferases, UDP-glucuronosyltransferases, and NADPH reductase (Larigot et al. 2018). It was recently reported that bacterial metabolites induce the expression of AhR and its target genes, including CYP1A1, CYP1A2 and CYP1B1 in GF mice liver (Korecka et al. 2016). We found that the expression of AhR was significantly decreased in the small intestine of SPF mice, which could explain the decrease in the expression of Cypla2, but the expression of AhR was not significantly changed in the small intestine of GF mice. These results highlight the importance of the gut microbiota in the regulation of 
Cypla2 synthesis, and that in the absence of the gut microbiota, the regulation pathway leading to the increased expression of Cypla2 may not be dependent on the AhR in the small intestine. Recently, several articles have appeared, pointing out the cross-regulatory circuit between the AhR and gut microbiota which affects the nutritional, immunological, and physiological status and impacts the host metabolism (Ji and Qu 2018, Natividad et al. 2018, Zhang et al. 2015) A wide range of effects are attributed to changes in bacterial tryptophan metabolism due to altered gut microbiota (Agus et al. 2018, Gao et al. 2018, Konopelski and Ufnal 2018). Moreover, the expression of another target gene of AhR, Cyplal, was increased by nabumetone in the liver of the GF but the SPF mice have shown opposite tendency. (Fig. 1A and 4A).

The another important enzyme in the metabolism of nabumetone in human is CYP3A4. We have found that the gene Cyp3a11 (the mouse orthologue of human CYP3A4) was overexpressed in the small intestine of SPF and GF mice by the application of nabumetone. These changes may be clinically important not only for nabumetone, as CYP3A4 is the most represented CYP enzyme in the human liver and in the small intestine, and, completely or partially, metabolizes the majority of all drugs in humans (Anzenbacher and Anzenbacherova 2001), thus, knowledge of the molecular mechanism behind these changes in regulation pathways is urgently needed.

We measured the expression of some transcriptional factors responsible for the regulation of the synthesis of CYPs. The expression of the CAR receptor involved in the regulation pathway of human CYP3A4 was not significantly affected by the application of nabumetone. On the other hand, the expression of PXR (participates in the CYP3A4 regulation pathway) is increased after the application of nabumetone in the liver and even more in the small intestine of SPF mice (Fig. 1B and 4B). The expression of PXR was not significantly affected in the liver and in the small intestine of GF mice by the administration of nabumetone. These divergent results highlight the differences in the regulation of CYPs as a response to drug exposure in the presence or absence of the gut microbiota. This clearly indicates that PXR may be responsible for the observed changes in the SPF mice, however crosstalk between other nuclear receptors could be crucial in the CYP3A expression in the liver as well in the small intestine. It should be noted that besides PXR and CAR, the vitamin D receptor (VDR) and peroxisome proliferator-activated receptor $\alpha(\operatorname{PPAR} \alpha)$ are suggested to be involved in the regulation of CYP3A4 expression in human adults (Betts et al. 2015).

The results of the expression of transcriptional factor Hnf4 revealed another interesting point in the regulation observed in several Cyp genes and proteins as different changes were observed in the liver and in the small intestine of SPF mice. Whereas the expression of Hnf4 in the liver of SPF mice after an oral dose of nabumetone significantly increased (Fig. 4B), we observed a significant decrease in its expression in the small intestine (Fig. 1B). Similar discrepancy is apparent in several CYPs mRNA expression in GF/SPF mice (Fig. 1A, 4A). The previous study has revealed, that the knock-out of hepatic CYP activity caused compensatory increases in the intestinal expression of the CYP2B, 2C, and $3 \mathrm{~A}$ proteins (Zhu et al. 2014). The hypothesis that CYP expression in the liver and intestine may be coordinately regulated to maintain the overall metabolic capacity for the first-pass metabolism of oral drugs was published recently (Xie et al. 2016). A possible mechanism was proposed using a mice model with suppressed hepatic CYPs due to deletion of the Cpr gene (NADPH-cytochrome P450 reductase). Mutual interactions of drugs and gut microbiota contribute to the final therapeutic effect of drugs. It has been found that nabumetone is metabolized by intestinal microbiota to its non-active metabolite (Jourova et al. 2016), furthermore, CYPs may be involved in its metabolism (Turpeinen et al. 2009). Now, to illustrate the complexity of this issue, we found that nabumetone itself influences the gene and protein expression and, in the case of some enzymes, enzymatic activity of CYPs in the intestine as well in the liver in the presence or absence of gut microbiota and, more interestingly, very often in different ways.

It follows that the induction of CYP at the level of mRNA expression is closely related to the regulation through nuclear receptors. However, this may not result in increased activity that would significantly interfere with possible pharmacotherapy. Levels of functional protein can be modified by studied xenobiotic through interference with protein degradation or protein stabilization by posttranslational mechanisms (Lin 2006). For example, microRNA regulate gene expression through mRNA degradation or the inhibition of protein translation (Gill et al. 2017). This underlines the importance of studies such as ours, where the effect on certain enzyme is monitored up to its functional form 
(Lněničková et al. 2018). Therefore, further studies are needed to explain which pathways participate in the regulation of CYP synthesis and what the detailed mechanism (including the direct and indirect effects of intestinal bacteria) involves.

\section{Conflict of Interest}

There is no conflict of interest.

\section{Acknowledgements}

This work was supported by The Czech Science Foundation (grant no. 19-08294S), the Internal Student Grant Agency of Palacký University, CZ (grant number IGA_LF_2020_022) and by project Toxicology CZ.02.2.69/0.0/0.0/16_018/0002311.

\section{Data availability statements}

The raw data supporting the conclusions of this manuscript will be made available by the authors, without undue reservation, to any qualified researcher.

\begin{abstract}
Abbreviations
AhR, aryl hydrocarbon receptor; CAR, constitutive androstane receptor; CYP, cytochromes P450; DMEs, drug metabolizing enzymes; GF, germ-free; GIT, gastrointestinal tract; Hnf4, hepatocyte nuclear factor 4; HPRT1, hypoxanthine phosphoribosyltransferase 1; NABU, nabumetone; SPF, specific pathogen-free; PPAR $\alpha$, peroxisome proliferator-activated receptor alpha; $\mathrm{PXR}$, pregnane $\mathrm{X}$ receptor; VDR, vitamin $\mathrm{D}$ receptor; 6-MNA, 6-methoxy-2-naphthylacetic acid
\end{abstract}

\section{References}

AGUS A, PLANCHAIS J, SOKOL H: Gut microbiota regulation of tryptophan metabolism in health and disease. Cell Host Microbe 23: 716-724, 2018. https://doi.org/10.1016/j.chom.2018.05.003

ANZENBACHER P, ANZENBACHEROVA E: Cytochromes P450 and metabolism of xenobiotics. CMLS 58: 737-747, 2001. https://doi.org/10.1007/PL00000897

BETTS S, BJORKHEM-BERGMAN L, RANE A, EKSTROM L: Expression of CYP3A4 and CYP3A7 in human foetal tissues and its correlation with nuclear receptors. Basic Clin Pharmacol Toxicol 117: 261-266, 2015. https://doi.org/10.1111/bcpt.12392

CHANG TK, WAXMAN DJ: Catalytic assays for human cytochrome P450: an introduction. Methods Mol Biol 320: 73-83, 2006. https://doi.org/10.1385/1-59259-998-2:73

CLAUS SP, ELLERO SL, BERGER B, KRAUSE L, BRUTTIN A, MOLINA J, PARIS A, WANT EJ, DE WAZIERS I, CLOAREC O, RICHARDS SE, WANG Y, DUMAS ME, ROSS A, REZZI S, KOCHHAR S, VAN BLADEREN P, LINDON JC, HOLMES E, NICHOLSON JK: Colonization-induced host-gut microbial metabolic interaction. mBio 2: e00271-00210, 2011. https://doi.org/10.1128/mBio.00271-10

COX LM, WEINER HL: Microbiota signaling pathways that influence neurologic disease. Neurotherapeutics 15 : 135-145, 2018. https://doi.org/10.1007/s13311-017-0598-8

FORSLUND K, HILDEBRAND F, NIELSEN T, FALONY G, LE CHATELIER E, SUNAGAWA S, PRIFTI E, VIEIRA-SILVA S, GUDMUNDSDOTTIR V, PEDERSEN HK, ARUMUGAM M, KRISTIANSEN K, VOIGT AY, VESTERGAARD H, HERCOG R, COSTEA PI, KULTIMA JR, LI J, JORGENSEN T, LEVENEZ F, DORE J, NIELSEN HB, BRUNAK S, RAES J, HANSEN T, WANG J, EHRLICH SD, BORK P, PEDERSEN O: Disentangling type 2 diabetes and metformin treatment signatures in the human gut microbiota. Nature 528: 262-266, 2015. https://doi.org/10.1038/nature15766

GAO J, XU K, LIU H, LIU G, BAI M, PENG C, LI T, YIN Y: Impact of the gut microbiota on intestinal immunity mediated by tryptophan metabolism. Front Cell Infect Microbiol 8: 13, 2018. https://doi.org/10.3389/fcimb.2018.00013

GILL P, BHATTACHARYYA S, MCCULLOUGH S, LETZIG L, MISHRA PJ, LUO C, DWEEP H, JAMES L: MicroRNA regulation of CYP 1A2, CYP3A4 and CYP2E1 expression in acetaminophen toxicity. Sci Rep 7: 12331, 2017. https://doi.org/10.1038/s41598-017-11811-y

GILLETTE J: Techniques for studying drug metabolism in vitro. In: Fundamentals of drug metabolism and drug disposition. BN LA DU, G MANDEL, EL WAY (eds.), Baltimore, Williams and Wilkins, 1971, pp 400-418.

GOETHEL A, CROITORU K, PHILPOTT DJ: The interplay between microbes and the immune response in inflammatory bowel disease. J Physiol 596: 3869-3882, 2018. https://doi.org/10.1113/JP275396 
JERNBERG C, LOFMARK S, EDLUND C, JANSSON JK: Long-term impacts of antibiotic exposure on the human intestinal microbiota. Microbiology 156: 3216-3223, 2010. https://doi.org/10.1099/mic.0.040618-0

JI J, QU H: Cross-regulatory circuit between AHR and microbiota. Curr Drug Metab 20: 4-8, 2019. https://doi.org/10.2174/1389200219666180129151150

JOUROVA L, ANZENBACHER P, ANZENBACHEROVA E: Human gut microbiota plays a role in the metabolism of drugs. Biomed Pap Med Fac Univ Palacky Olomouc Czech Rep 160: 317-326, 2016. https://doi.org/10.5507/bp.2016.039

JOUROVA L, ANZENBACHER P, LISKOVA B, MATUSKOVA Z, HERMANOVA P, HUDCOVIC T, KOZAKOVA H, HRNCIROVA L, ANZENBACHEROVA E: Colonization by non-pathogenic bacteria alters mRNA expression of cytochromes P450 in originally germ-free mice. Folia Microbiol 62: 463-469, 2017. https://doi.org/10.1007/s12223-017-0517-8

JOUROVA L, ANZENBACHER P, MATUSKOVA Z, VECERA R, STROJIL J, KOLAR M, NOBILIS M, HERMANOVA P, HUDCOVIC T, KOZAKOVA H, KVERKA M, ANZENBACHEROVA E: Gut microbiota metabolizes nabumetone in vitro: Consequences for its bioavailability in vivo in the rodents with altered gut microbiome. Xenobiotica 49: 1296-1302, 2019. https://doi.org/10.1080/00498254.2018.1558310

KAMINSKY LS, ZHANG Q-Y: The small intestine as a xenobiotic-metabolizing organ. Drug Metab Dispos 31: 1520-1525, 2003. https://doi.org/10.1124/dmd.31.12.1520

KOETH RA, WANG Z, LEVISON BS, BUFFA JA, ORG E, SHEEHY BT, BRITT EB, FU X, WU Y, LI L, SMITH JD, DIDONATO JA, CHEN J, LI H, WU GD, LEWIS JD, WARRIER M, BROWN JM, KRAUSS RM, TANG WH, BUSHMAN FD, LUSIS AJ, HAZEN SL: Intestinal microbiota metabolism of L-carnitine, a nutrient in red meat, promotes atherosclerosis. Nat Med 19: 576-585, 2013. https://doi.org/10.1038/nm.3145

KONOPELSKI P, UFNAL M: Indoles - gut bacteria metabolites of tryptophan with pharmacotherapeutic potential. Curr Drug Metab 19(10): 883-890, 2018. https://doi.org/10.2174/1389200219666180427164731

KOOPEN AM, GROEN AK, NIEUWDORP M: Human microbiome as therapeutic intervention target to reduce cardiovascular disease risk. Curr Opin Lipidol 27: 2016. https://doi.org/10.1097/MOL.0000000000000357

KORECKA A, DONA A, LAHIRI S, TETT AJ, AL-ASMAKH M, BRANISTE V, D'ARIENZO R, ABBASPOUR A, REICHARDT N, FUJII-KURIYAMA Y, RAFTER J, NARBAD A, HOLMES E, NICHOLSON J, ARULAMPALAM V, PETTERSSON S: Bidirectional communication between the Aryl hydrocarbon Receptor (AhR) and the microbiome tunes host metabolism. NPJ Biofilms Microbiomes 2: 16014, 2016. https://doi.org/10.1038/npjbiofilms.2016.14

LARIGOT L, JURICEK L, DAIROU J, COUMOUL X: AhR signaling pathways and regulatory functions. Biochim Open 7: 1-9, 2018. https://doi.org/10.1016/j.biopen.2018.05.001

LI H, HE J, JIA W: The influence of gut microbiota on drug metabolism and toxicity. Expert Opin Drug Metab Toxicol 12: 31-40, 2016. https://doi.org/10.1517/17425255.2016.1121234

LIN JH: CYP induction-mediated drug interactions: in vitro assessment and clinical implications. Pharm Res 23: 1089-1116, 2006. https://doi.org/10.1007/s11095-006-0277-7

LIVAK KJ, SCHMITTGEN TD: Analysis of relative gene expression data using real-time quantitative PCR and the 2(-Delta Delta C(T)) Method. Methods 25: 402-408, 2001. https://doi.org/10.1006/meth.2001.1262

LNĚNIČKOVÁ K, SKÁLOVÁ L, STUCHLÍKOVÁ L, SZOTÁKOVÁ B, MATOUŠKOVÁ P: Induction of xenobiotic-metabolizing enzymes in hepatocytes by beta-naphthoflavone: Time-dependent changes in activities, protein and mRNA levels. Acta Pharm 68: 75-85, 2018. https://doi.org/10.2478/acph-2018-0005

MATUSKOVA Z, ANZENBACHEROVA E, VECERA R, TLASKALOVA-HOGENOVA H, KOLAR M, ANZENBACHER P: Administration of a probiotic can change drug pharmacokinetics: effect of E. coli Nissle 1917 on amidarone absorption in rats. PLoS ONE 9: e87150, 2014. https://doi.org/10.1371/journal.pone.0087150 
NATIVIDAD JM, AGUS A, PLANCHAIS J, LAMAS B, JARRY AC, MARTIN R, MICHEL ML, CHONGNGUYEN C, ROUSSEL R, STRAUBE M, JEGOU S, MCQUITTY C, LE GALL M, DA COSTA G, LECORNET E, MICHAUDEL C, MODOUX M, GLODT J, BRIDONNEAU C, SOVRAN B, DUPRAZ L, BADO A, RICHARD ML, LANGELLA P, HANSEL B, LAUNAY JM, XAVIER RJ, DUBOC H, SOKOL H: Impaired aryl hydrocarbon receptor ligand production by the gut microbiota is a key factor in metabolic syndrome. Cell Metab 28:737-749.e4. 2018. https://doi.org/10.1016/j.cmet.2018.07.001

NOBILIS M, MIKUSEK J, SZOTAKOVA B, JIRASKO R, HOLCAPEK M, CHAMSEDDIN C, JIRA T, KUCERA R, KUNES J, POUR M: Analytical power of LLE-HPLC-PDA-MS/MS in drug metabolism studies: identification of new nabumetone metabolites. J Pharm Biomed 80: 164-172, 2013. https://doi.org/10.1016/j.jpba.2013.03.006

PHILLIPS IR, SHEPHARD EA: Cytochrome P450 Protocols. Humana Press, Totowa, NJ. 2006, 320: 364.

SAAD R, RIZKALLAH MR, AZIZ RK: Gut Pharmacomicrobiomics: the tip of an iceberg of complex interactions between drugs and gut-associated microbes. Gut Pathog 4: 16, 2012. https://doi.org/10.1186/1757-4749-4-16

SELWYN FP, CUI JY, KLAASSEN CD: RNA-Seq quantification of hepatic drug processing genes in germ-free mice. Drug Metab Dispos 43: 1572-1580, 2015. https://doi.org/10.1124/dmd.115.063545

SELWYN FP, CHENG SL, KLAASSEN CD, CUI JY: Regulation of hepatic drug-metabolizing enzymes in germ-free mice by conventionalization and probiotics. Drug Metab Dispos 44: 262-274, 2016. https://doi.org/10.1124/dmd.115.067504

SOUSA T, PATERSON R, MOORE V, CARLSSON A, ABRAHAMSSON B, BASIT AW: The gastrointestinal microbiota as a site for the biotransformation of drugs. Int $J$ Pharm 363: 1-25, 2008. https://doi.org/10.1016/j.ijpharm.2008.07.009

TURPEINEN M, HOFMANN U, KLEIN K, MURDTER T, SCHWAB M, ZANGER UM: A predominate role of CYP1A2 for the metabolism of nabumetone to the active metabolite, 6-methoxy-2-naphthylacetic acid, in human liver microsomes. Drug Metab Dispos 37: 1017-1024, 2009. https://doi.org/10.1124/dmd.108.025700

VARFAJ F, ZULKIFLI SN, PARK HG, CHALLINOR VL, DE VOSS JJ, ORTIZ DE MONTELLANO PR: Carboncarbon bond cleavage in activation of the prodrug nabumetone. Drug Metab Dispos 42: 828-838, 2014. https://doi.org/10.1124/dmd.114.056903

WILKINSON EM, ILHAN ZE, HERBST-KRALOVETZ MM: Microbiota-drug interactions: Impact on metabolism and efficacy of therapeutics. Maturitas 112: 53-63, 2018. https://doi.org/10.1016/j.maturitas.2018.03.012

WILSON ID, NICHOLSON JK: Gut microbiome interactions with drug metabolism, efficacy, and toxicity. Transl Res 179: 204-222, 2017. https://doi.org/10.1016/j.trsl.2016.08.002

XIE F, DING X, ZHANG QY: An update on the role of intestinal cytochrome P450 enzymes in drug disposition. Acta Pharm Sin B 6: 374-383, 2016. https://doi.org/10.1016/j.apsb.2016.07.012

YOO DH, KIM IS, VAN LE TK, JUNG IH, YOO HH, KIM DH: Gut microbiota-mediated drug interactions between lovastatin and antibiotics. Drug Metab Dispos 42: 1508-1513, 2014. https://doi.org/10.1124/dmd.114.058354

ZANGER UM, SCHWAB M: Cytochrome P450 enzymes in drug metabolism: regulation of gene expression, enzyme activities, and impact of genetic variation. Pharmacol Therapeut 138: 103-141, 2013. https://doi.org/10.1016/j.pharmthera.2012.12.007

ZHANG L, NICHOLS RG, CORRELL J, MURRAY IA, TANAKA N, SMITH PB, HUBBARD TD, SEBASTIAN A, ALBERT I, HATZAKIS E, GONZALEZ FJ, PERDEW GH, PATTERSON AD: Persistent organic pollutants modify gut microbiota-host metabolic homeostasis in mice through aryl hydrocarbon receptor activation. Environ Health Perspect 123: 679-688, 2015. https://doi.org/10.1289/ehp.1409055

ZHU Y, DING X, FANG C, ZHANG QY: Regulation of intestinal cytochrome P450 expression by hepatic cytochrome P450: possible involvement of fibroblast growth factor 15 and impact on systemic drug exposure. Mol Pharmacol 85: 139-147, 2014. https://doi.org/10.1124/mol.113.088914 